\title{
ANALISIS PENGARUH KEPUASAN KERJA TERHADAP KINERJA KARYAWAN PADA PT TIMBUL MANDIRI JAYA BOYOLALI TAHUN 2019
}

\author{
Aan Irfan Adiyanto ${ }^{1}$, Nuning Lisdiana ${ }^{2}$, Una Ria Safitri $^{3}$ \\ aanirfanadivanto@gmail.com \\ Universitas Boyolali
}

\begin{abstract}
Within a company, employees are one of the most valuable assets. Employees are human resources that drive companies to compete with other companies. Employees who have satisfaction in working will certainly be able to increase performance productivity and achieve the goals set by the company. PT Timbul Mandiri Jaya Boyolali is a company engaged in the automotive sector which is addressed at Jalan Boyolali Semarang KM 1, Winong Village, Boyolali District, Boyolali Regency. PT Timbul Mandiri Jaya Boyolali sells Honda motorcycle products and serves Honda motorcycle services. PT Timbul Mandiri Jaya Boyolali is the largest Honda motorcycle dealer in the city of Boyolali which has 75 employees both sales and ahass, because it has quite a lot of employees of course need good management so that employees get satisfaction in working, this causes an influence on employee performance working at PT Timbul Mandiri Jaya Boyolali. This study aims to determine the effect of job satisfaction on employee performance at PT Timbul Mandiri Jaya Boyolali and which job satisfaction variables most influence employee performance at PT Timbul Mandiri Jaya Boyolali. This research was conducted at PT Timbul Mandiri Jaya Boyolali, a research period of 3 months by distributing several questionnaires with the object of Timbul Jaya Motor employees as many as 75 correspondents. Methods of collecting data using questionnaires. Analysis of the data used is multiple regression analysis and significance testing using $t$ and $F$ tests. The results show that there is no positive and significant effect of salary, the job itself, promotion and coworkers on employee performance, while the supervisory variable has a positive and significant influence on employee performance with $t$ table $<$ t_count with a significance of more than $5 \%$ or 0.05
\end{abstract}

Keywords : Salary, Employment, Promotion, Colleagues, Supervision, and Employee Performance.

\section{PENDAHULUAN}

\subsection{Latar Belakang}

Di era globalisasi saat ini teknologi dan komunikasi berkembang sangat pesat sehingga memberikan perubahan yang sangat signifikan dalam penerapan keseharian di setiap perusahaan. Di dalam suatu perusahaan karyawan adalah salah satu aset yang sangat berharga. Karyawan berkedudukan sebagai sumber daya manusia yang dapat menjadi penggerak perusahaan dalam mencapai tujuan.

Produktivitas sumber daya manusia salah satunya ditunjuang oleh kepuasan kerja. Kepuasan kerja sendiri merupakan penilaian dari pekerja yaitu seberapa jauh pekerjaannya atau keseluruhan memuaskan kebutuhannya dan secara umum dapat diberi batasan sebagai perasaan seseorang terhadap pekerjaanya. Kepuasan kerja berhubungan erat dengan sikap dari karyawan 
terhadap pekerjaannya sendiri, situasi kerja, kerja sama antar pimpinan dan dengan sesama karyawan. Kepuasan kerja mencerminkan perasaan seseorang terhadap pekerjaannya.

Sebagai tindak lanjut dari kepuasan kerja, kinerja merupakan hal yang menjadi ukuran penilaian perusahaan terhadap karyawan tersebut. Kinerja adalah hasil kerja secara kualitas dan kuantitas yang dicapai oleh seorang pegawai dalam melaksanakan tugasnya sesuai dengan tanggung jawab yang diberikan kepadanya. PT Timbul Mandiri Jaya Boyolali memiliki total 75 karyawan baik dari Ahass maupun Showroom. Oleh karena itu penting bagi PT Timbul Mandiri Jaya Boyolali untuk dapat memotivasi karyawannya agar dapat bekerja secara maksimal dalam melayani konsumen pembelian motor maupun service motor honda. Apabila karyawan puas dengan pekerjaan mereka, secara tidak langsung juga akan berdampak pada pelayanan konsumen yang semakin baik dan dapat meningkatkan kinerja karyawan serta nilai positif konsumen kepada perusahaan. Melihat bahwa dealer ini merupakan salah satu dealer yang besar dan memiliki karyawan yang cukup banyak, maka penulis dapat mengambil judul

"ANALISIS

PENGARUH KEPUASAN KERJA

TERHADAP

KINERJA KARYAWAN PADA PT TIMBUL MANDIRI BOYOLALI".

\subsection{PERUMUSAN MASALAH}

Berdasarkan latar belakang di atas, penulis dapat merumuskan beberapa masalah penelitian sebagai berikut:

1. Apakah secara simultan kepuasan kerja meliputi gaji (X1), pekerjaan itu sendiri (X2), promosi (X3), rekan kerja (X4) dan pengawasan (X5) berpengaruh terhadap kinerja karyawan pada PT Timbul Mandiri Jaya Boyolali?

2. Apakah secara parsial kepuasan kerja meliputi gaji (X1), pekerjaan itu sendirib(X2), promosi (X3), rekan kerja (X4) dan pengawasan (X5) berpengaruh terhadap kinerja karyawan pada PT Timbul Mandiri Jaya Boyolali?

\section{KAJIAN LITERATUR DAN PENGEMBANGAN HIPOTESIS}

\subsection{Landasan Teori Kepuasan Kerja}

Menurut Malayu S.P. Hasibuan (2002:202) kepuasan kerja adalah sikap emosional yang menyenangkan dan mencintai pekerjaannya. Sikap ini dicerminkan oleh moral kerja, kedisiplinan, 
dan prestasi kerja. Kepuasan kerja dinikmati dalam pekerjaan, luar pekerjaan, dan kombinasi dalam dan luar pekerjaan.

\section{Kinerja}

Menurut Mangkunegara (2014:9) kinerja karyawan adalah apa yang dilakukan atau tidak dilakukan karyawan yang mempengaruhi seberapa besar banyaknya mereka member kontribusi kepada organisasi secara kualitas output, kuantitas output, jangka waktu output, kehadiran ditempat kerja, dan sikap kooperatif.

\section{Gaji}

Gaji / Upah (pay), yaitu

merupakan faktor
multidimensi dalam kepuasan kerja. Sejumlah upah/ uang yang diterima karyawan menjadi penilaian untuk kepuasan, dimana hal ini bisa dipandang sebagai hal yang dianggap pantas dan layak.

\section{Pekerjaan Itu Sendiri}

Pekerjaan itu sendiri (work it self), yaitu merupakan sumber utama kepuasan dimana pekerjaan tersebut memberikan tugas yang menarik, kesempatan untuk belajar, kesempatan untuk menerima tanggung jawab dan kemajuan untuk karyawan.

\section{Promosi}

Promosi (promotion), yaitu kesempatan untuk
Berkembang secara intelektual dan memperluas keahlian menjadi dasar perhatian penting untuk maju dalam organisasi sehingga menciptakan kepuasan.

\section{Rekan Kerja}

Rekan kerja (workers), yaitu rekan kerja yang kooperatif merupakan sumber kepuasan kerja yang paling sederhana. Kelompok kerja, terutama tim yang kompak bertindak sebagai sumber dukungan, kenyamanan, nasehat, dan bantuan pada anggota individu.

\section{Pengawasan}

Pengawasan (supervision), yaitu merupakan kemampuan penyelia untuk memberikan bantuan teknik dan dukungan perilaku. Pertama adalah berpusat pada karyawan, diukur menurut tingkat dimana penyelia menggunakan ketertarikan personal dan peduli pada karyawan.Kedua adalah iklim partisipasi atau pengaruh dalam

pengambilan keputusan yang dapat mempengaruhi pekerjaan karyawan.

\subsection{Pengembangan Hipotesis}

Berdasarkan perumusan masalah di atas maka dapat diperoleh jawaban hipotesis adalah sebagai berikut: 
Ho : Tidak terdapat pengaruh yang signifikan dari gaji, pekerjaan itu sendiri, promosi, rekan kerja dan pengawasan terhadap kinerja karyawan pada PT Timbul Mandiri Jaya Boyolali secara silmutan.

$\mathrm{Ha}$ : Terdapat pengaruh yang signifikan dari gaji, pekerjaan itu sendiri, promosi, rekan kerja dan pengawasan terhadap kinerja karyawan pada PT Timbul Mandiri Jaya Boyolali secara silmutan.

Ho : Tidak terdapat pengaruh yang signifikan dari gaji, pekerjaan itu sendiri, promosi, rekan kerja dan pengawasan terhadap kinerja karyawan pada PT Timbul Mandiri Jaya Boyolali secara parsial.

$\mathrm{Ha}$ : Terdapat pengaruh yang signifikan dari gaji, pekerjaan itu sendiri, promosi, rekan kerja dan pengawasan terhadap kinerja karyawan pada PT Timbul Mandiri Jaya Boyolali secara parsial.

\section{METODE ANALISIS DATA}

Berdasarkan jenis data yang digunakan, penelitian ini merupakan penelitian kuantitatif, sedangkan berdasarkan bentuk penelitiannya, penelitian ini merupakan asosiasi karena menganalisa pengaruh variabel independen terhadap variabel dependen. Metode pengumpulan data yang digunakan dalam penelitian adalah dengan menyebar kuisioner kepada responden yaitu karyawan PT Timbul Mandiri Jaya Boyolali. Data yang digunakan dalam penelitian ini adalah data primer hasil jawaban kuisioner. Teknik analisa yang digunakan dalam penelitian ini adalah uji asumsi klasik, uji regresi linear berganda, uji $\mathrm{F}$, uji $\mathrm{t}$, dan uji koefisien determinasi.

Adapun model persamaan regresi linear adalah sebagai

berikut:

$\mathrm{KK}=\alpha+\mathrm{B}_{1} \mathrm{G}+\mathrm{B}_{2} \mathrm{P}+\mathrm{B}_{3} \mathrm{PR}+\mathrm{B}_{4} \mathrm{RK}$

$+\mathrm{B}_{5} \mathrm{PN}+\mathrm{e}$

Dimana:

$$
\begin{array}{ll}
\mathrm{KK} & =\text { Kinerja Karyawan } \\
\alpha & =\text { Konstanta } \\
\mathrm{G} & =\text { Gaji } \\
\mathrm{P} & =\text { Pekerjaan itu sendiri } \\
\mathrm{PR} & =\text { Promosi } \\
\mathrm{RK} & =\text { Rekan Kerja } \\
\mathrm{PN} & =\text { Pengawasan } \\
\mathrm{E} & =\text { eror }
\end{array}
$$

\section{HASIL ANALISIS}

Hasil analisis data menghasilkan nilainilai yang digunakan untuk membuktikan hipotesis dari penelitian, yaitu sebagai berikut :
a. Hipotesis Pertama
Uji F, digunakan apakah kepuasan kerja yang meliputi gaji, pekerjaan itu sendiri, promosi, rekan kerja dan pengawasan secara simulta berpengaruh terhadap kinerja karyawan

\section{Hasil Uji F ANOVA $^{\mathrm{a}}$}

\begin{tabular}{|l|c|r|r|r|r|}
\hline $\begin{array}{l}\text { Mod } \\
\text { el }\end{array}$ & $\begin{array}{c}\text { Sum of } \\
\text { Squares }\end{array}$ & Df & $\begin{array}{c}\text { Mean } \\
\text { Square }\end{array}$ & F & Sig. \\
\hline $\begin{array}{l}\text { Regr } \\
\text { essio } \\
\mathrm{n}\end{array}$ & 103.591 & 5 & 20.718 & 8.987 & $.000^{\mathrm{b}}$ \\
$\begin{array}{l}\text { Resi } \\
\text { dual }\end{array}$ & 159.076 & 69 & 2.305 & & \\
Total & 262.667 & 74 & & & \\
\hline
\end{tabular}


Dari hasil pengujian ini pada tabel diatas bahwa Sig. 0,000 $<0,05$ hal ini menunjukkan bahwa semua variabel berpengaruh secara 1 . silmutan.

Dengan menggunakan tingkat $\square$ ( alfa ) 0,05 atau $5 \%$ maka Ho berhasil di tolak dan Ha gagal di tolak. Penolakan Ho dibuktikan dengan hasil perhitungan bahwa nilai sig $(0,000)<$ dari $\square$ ( alfa $)=0,05$ sehingga dapat disimpulkan bahwa semua variabel secara silmutan mempengaruhi kinerja karyawan di PT Timbul Mandiri Jaya Boyolali.

b. Hipotesis Kedua Uji t digunakan apakah kepuasan kerja yang meliputi gaji, pekerjaan itu sendiri, promosi, rekan kerja dan pengawasan secara parsial berpengaruh terhadap kinerja karyawan.

\begin{tabular}{|c|c|c|c|}
\hline \multicolumn{4}{|c|}{ Hasil Uji t } \\
\hline Variabel & $\mathbf{T}$ & Sig & Keterangan \\
\hline Gaji & $\begin{array}{l}1.5 \\
99\end{array}$ & $\begin{array}{c}0.1 \\
14\end{array}$ & $\begin{array}{c}\text { Tidak } \\
\text { signifikan }\end{array}$ \\
\hline $\begin{array}{c}\text { Pekerjaa } \\
\text { n Itu } \\
\text { Sendiri }\end{array}$ & $\begin{array}{l}1.6 \\
43\end{array}$ & $\begin{array}{l}0.1 \\
05\end{array}$ & $\begin{array}{c}\text { Tidak } \\
\text { signifikan }\end{array}$ \\
\hline Promosi & $\begin{array}{l}1.5 \\
79\end{array}$ & $\begin{array}{l}0.1 \\
19\end{array}$ & $\begin{array}{c}\text { Tidak } \\
\text { signifikan }\end{array}$ \\
\hline $\begin{array}{c}\text { Rekan } \\
\text { Kerja }\end{array}$ & $\begin{array}{l}- \\
0,0 \\
33 \\
\end{array}$ & $\begin{array}{l}0.9 \\
73\end{array}$ & $\begin{array}{c}\text { Tidak } \\
\text { signifikan }\end{array}$ \\
\hline $\begin{array}{l}\text { Pengawas } \\
\text { an }\end{array}$ & $\begin{array}{l}2.4 \\
25\end{array}$ & $\begin{array}{c}0.0 \\
18\end{array}$ & Signifikan \\
\hline
\end{tabular}

Berdasarkan tabel diatas maka dapat dijelaskan sebagai berikut :

1. Analisis terhadap variabel gaji Untuk variabel gaji, apabila Sig. $0,000>$ Sig. 0,005

maka $\mathrm{H}_{\mathrm{o}}$ di terima dan $\mathrm{H}_{\mathrm{a}}$ di tolak. Nilai Sig. 0.114 hal ini menunjukkan bahwa variabel gaji secara

parsial tidak berpengaruh terhadap kinerja karyawan, dengan kata lain variabel gaji tidak mempunyai pengaruh signifikan terhadap kinerja karyawan.

2. Analisis terhadap variabel pekerjaan itu sendiri

Untuk variabel pekerjaan itu sendiri, apabila Sig. 0,000 > Sig. 0,005 maka $\mathrm{H}_{\mathrm{o}}$ di terima dan $\mathrm{H}_{\mathrm{a}}$ di tolak. Nilai Sig. 0.105

hal ini menunjukkan bahwavariabel pekerjaan itu sendiri secara parsial tidak berpengaruh terhadap kinerja karyawan, dengan kata lain variabel pekerjaan itu sendiri tidak mempunyai pengaruh signifikan terhadap kinerja karyawan.

3. Analisis terhadap variabel promosi

Untuk variabel promosi, apabila Sig 
$0,000>$ Sig. 0,005

maka $\mathrm{H}_{\mathrm{o}}$ di terima dan $\mathrm{H}_{\mathrm{a}}$ di tolak. Nilai Sig. 0.119 hal ini menunjukkan bahwa variabel promosi

secara parsial tidak berpengaruh terhadap kinerja karyawan, dengan kata lain variabel promosi tidak mempunyai pengaruh signifikan terhadap kinerja karyawan.

4. Analisis terhadap variable rekan kerja Untuk variabel rekan kerja, apabila Sig. $0,000>$ Sig. 0,005 maka $\mathrm{H}_{0}$ di terima dan $\mathrm{H}_{\mathrm{a}}$ di tolak. Nilai Sig. 0.973 hal ini menunjukkan bahwa variabel rekan kerja secara parsial

tidak berpengaruh terhadap kinerja karyawan, dengan kata lain variabel rekan kerja tidak mempunyai pengaruh signifikan terhadap kinerja karyawan.

5. Analisis terhadap variable pengawasan

Untuk variabel pengawasan, apabila Sig. $0,000>$ Sig.

0,005 maka $\mathrm{H}_{\mathrm{o}}$ di terima dan $\mathrm{H}_{\mathrm{a}}$ di tolak. Nilai Sig.0,018 hal ini menunjukkan bahwa variabel pengawasan secara

parsial berpengaruh terhadap kinerja karyawan, dengan kata lain variabel pengawasan mempunyai pengaruh signifikan terhadap kinerja Karyawan.

\section{KESIMPULAN}

Berdasarkan hasil analisa data dan pembahasan di atas, dapat penulis tarik beberapa kesimpulan sebagai berikut:

1. Berdasarka hasil perhitungan diperoleh nilai $\mathrm{t}_{\text {hitung }} 1.599>$ dari $\mathrm{t}$ tabel 0.277 dan nilai signifikan $0.114>0.05$ maka $\mathrm{H}_{\mathrm{o}}$ diterima sehingga variabel gaji tidak berpengaruh secara signifikan terhadap kinerja karyawan pada PT Timbul Mandiri Jaya Boyolali.

2. Berdasarkan hasil perhitungan diperoleh nilai t hitung $1.643>$ dari $\mathrm{t}$ tabel 0.277 dan nilai signifikan $0.105>0.05$ maka $\mathrm{H}_{\mathrm{o}}$ diterima sehingga variabel pekerjaan itu sendiri tidak berpengaruh secara signifikan terhadap kinerja karyawan pada PT Timbul Mandiri Jaya Boyolali.

3. Berdasarkan hasil perhitungan diperoleh nilai $t$

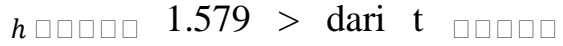
0.277 dan nilai signifikan 0.119 $>0.05$

maka $\mathrm{H}_{\mathrm{o}}$ diterima sehingga variabel promosi tidak berpengaruh secara signifikan terhadap kinerja karyawan pada PT Timbul Mandiri Jaya Boyolali.

4. Berdasarkan hasil Perhitungan diperoleh. nilai $\mathrm{t}$ hitung $-0.033<$ dari $\mathrm{t}_{\text {tabel }} 0.277$ dan nilai signifikan $0.973>0.05$ maka $\mathrm{H}_{\mathrm{o}}$ diterima sehingga variabel rekan kerja tidak berpengaruh secara signifikan terhadap kinerja karyawan pada PT Timbul Mandiri Jaya Boyolali.

5. Berdasarkan hasil perhitungan di peroleh nilai $\mathrm{t}_{\text {hitung }}$ $2.424>$ dari t tabel 0.277 dan nilai signifikan $0.018<0.05$ maka $\mathrm{H}_{\mathrm{o}}$ ditolak sehingga variabel pengawasan berpengaruh positif dan signifikan terhadap kinerja karyawan pada PT Timbul Mandiri Jaya Boyolali.

6. Dari hasil uji t, menunjukkan bahwa variable gaji, variabel pekerjaan itu sendiri, variabel promosi dan variabel rekan kerja secara parsial tidak memiliki pengaruh yang signifikan terhadap kinerja karyawan pada PT Timbul Mandiri Jaya Boyolali. Sedangkan variabel pengawasan secara parsial memiliki pengaruh yang signifikan terhadap kinerja karyawan pada PT Timbul Mandiri Jaya Boyolali.

7. Berdasarkan hasil uji t, menunjukkan bahwa variabel yang paling berpengaruh terhadap kinerja karyawan adalah variabel pengawasa 
8. Berdasarkan perhitungan nilai $\mathrm{R}$ Square sebesar 0.394. hal ini menunjukkan bahwa variabel gaji, pekerjaan itu sendiri, promosi, rkan kerja dan pengawasan secara bersamasama mampu menjelaskan variabel kinerja karyawan sebesar $39.4 \%$ selebihnya $60.6 \%$ dijelaskan oleh variabel-variabel lainseperti gaya kepemimpinan, bonus, sistem kerja dan lain-lain di luar variabel-variabel yang di teliti dalam penelitian ini.

\section{DAFTAR PUSTAKA}

Siagian, P. Sondang. 2016. Manajemen Sumber Daya Manusia. Jakarta : Bumi Aksara

Dessler, Garry. 2009. Manajemen Sumber Daya Manusia. Jakarta : PT Indeks

Sumarjo, Mahendro. Dan Donni Juni Priansa. 2018. Manajemen Pengembangan Sumber Daya Manusia (KonsepKonsep Kunci). Jakarta : Media Citra

R, Supomo dan Eti Nurhayati. 2018. Manajemen Sumber Daya Manusia (Untuk Mahasiswa dan Umum). Bandung : Yrama Widya

Handoko, T. Hani. 2016. Manajemen (Edisi Kedua). Yogyakarta : BPFE-Yogyakarta

Hasibuan, Malayu S.P. 2002. Manajemen Sumber Daya Manusia (Edisi Revisi). Jakarta

: Bumi Aksara

Bohlarander, George and Snell. 2010. Principles of Human Resource, Management. South

\section{Western : $\mathrm{OH}$}

Sofyandi. 2009. Manajemen Sumber Daya Manusia. Jakarta : PT. Indeks

Sugiyono. 2008. Satatistika Untuk Penelitian. Bandung : Alfabeta

Sutrisno, Edy. 2011. Manajemen Sumber Daya Manusia. Jakarta : Kencana

Sutrisno, Edy. 2014. Manajemen Sumber Daya Manusia (Edisi Kedua). Jakarta : Kencana

Bangun, Wilson. 2012. Manajemen Sumber Daya Manusia. Jakarta : Erlangga

Robbins, Stephen P. dan Timoty A. Judge. 2013. Perilaku Organisasi (alih Bahasa Puspitawati), Edisi Bahasa Indonesia. Jakarta : Media Chandra

Mangkunegara, A.A. Anwar Prabu. 2014. Manajemen Sumber Daya Manusia. Bandung : Rosda

Moeheriono. 2012. Pengukuran Kinerja Berbasis Kompetensi. Jakarta : Raja Grafindo Persada

Wirawan. 2009. Evaluasi Kinerja Sumber Daya Manusia Teori Aplikasi dan Penelitian. Jakarta : Salemba Empat

Rivai, Veithzal. 2011. Manajemen Sumber Daya Manusia Untuk Perusahaan : dari Teori ke Praktik. Jakarta : Raja Grafindo Persada

Robbins, Stephen P. dan Garry Dessler. 2012. Perilaku Organisasi (Edisi Ke-12, Alih Bahasa Prahartanto). Jakarta : Salemba Empat

Kreitner, Robert dan Angelo Kinicki. 2005. Perilaku Organisasi Buku I Edisi 5. Jakarta : Salemba Empat. 